\title{
The role of the International Commission for Optics (ICO) in optics training and education
}

\section{Alexander Sawchuk, Arthur Guenther}

Alexander A. Sawchuk, Arthur H. Guenther, "The role of the International Commission for Optics (ICO) in optics training and education," Proc. SPIE 9663, Eighth International Topical Meeting on Education and Training in Optics and Photonics, 966302 (6 October 2003); doi: 10.1117/12.2208369

EDent: Eighth International Topical Meeting on Education and Training in Optics and Photonics, 2003, Tucson, Arizona, United States 


\title{
The role of the International Commission for Optics (ICO) in optics training and education
}

\author{
Alexander A. Sawchuk \\ Signal and Image Processing Institute, University of Southern California, 3740 McClintock Avenue, Los Angeles, CA 90089-2564 \\ telephone: 213-740-4622; fax: 213-740-4651; e-mail: sawchuk@sipi.usc.edu
}

Arthur H. Guenther

Center for High Technology Materials, University of New Mexico, Albuquerque, NM 87131 telephone: 505-272-7003; fax: 505-272-7801; e-mail:agun@chtm.unm.edu

\begin{abstract}
ICO coordinates the advancement and dissemination of scientific and technical knowledge in optics and photonics. Its Education Committee plans to survey, cross-reference and provide web links for syllabi, curricula, course materials, laboratory experiments and textbooks for K-12 through professional educational programs. We invite discussion and comment on near-term and long-term goals.

(C)2003 Optical Society of America

OCIS codes: (000.2060) Education
\end{abstract}

\section{Summary}

The International Commission for Optics (ICO) is the primary world-wide international group that coordinates the advancement and dissemination of scientific and technical knowledge in the broad fields of optics and photonics [1]. ICO plays a unique role among world optics and photonics organizations. Its membership consists of 48 territorial and national members and six international society members, thus ensuring global geographical, engineering and scientific representation. ICO organizes and sponsors conferences, workshops, awards, traveling lecturers, publishing and educational programs.

In recent years, ICO activities have focused on developing nations, particularly in Africa, Central America and South America. The Education and Training in Optics and Photonics (ETOPS) series of meetings was originated and has been sponsored by ICO for many years. The scope of ETOPS includes education at all levels, from K-12 to technician and professional levels. To expand and organize these activities in the future, ICO has recently established an Education Committee. The role of this committee is to serve as a facilitator for improved international coordination and collaboration in optics and photonics education and training.

One future role for the ICO Education Committee is to provide information about optics and photonics education programs. ICO does not have the resources to produce an extensive list of education and training programs, but it can serve as a central initial contact and a web site index engine that to points to other lists of programs as well as specific programs at various institutions. As a starting point, both the Optical Society of America (OSA) [2] and the International Society for Optical Engineering (SPIE) [3] have lists of degree programs in optics on their web sites. Another role for this committee is to provide references to standard optics and photonics educational standards and curricula in use at locations world-wide. For example, there are syllabi for technician level programs listed by the Center for Occupational Research and Development (CORD) in their STEP II program [4]. The ICO Education committee can survey, cross-reference and provide web links for optics and photonics educational syllabi, curricula, course materials, laboratory experiments and textbooks for various levels. At the technician level, ICO can help to unify, disseminate and standardize the work of CORD and other optics societies in setting skill standards for optics technicians.

Optics kits and other materials for laboratory experiments (particularly at the K-12 level) are available from commercial and professional organizations. While the lab manuals for some of these kits are available in English, Spanish and French, one future role for the ICO Education Committee is to facilitate their translation into other languages. In addition, the ICO can organize and coordinate the free or low cost distribution of these kits in developing nations. A final role for ICO Education is to provide a world wide forum for the discussion and dissemination of optics and photonics educational knowledge. This forum can be implemented via the web, an email list server, or other electronic means.

Eighth International Topical Meeting on Education and Training in Optics and Photonics,

edited by Barry L. Shoop, Grover Swartzlander Jr., Proc. of SPIE Vol. 9663, 966302

(C) 2003 SPIE, OSA, ICO · doi: 10.1117/12.2208369

Proc. of SPIE Vol. $9663966302-1$ 
The ICO and its education activities are vital to the continued development of optics and photonics in the 21 st century. To carry them out requires help from many volunteers and resources from commercial supporters and foundations. In this paper we present future plans for these activities and information about the goals and mission of ICO. We invite discussion and comment from the optics and photonics community on near-term and long-term goals and activities of the ICO Education Committee.

\section{References}

1. International Commission for Optics (ICO) web site: http://www.ico-optics.org

2. Optical Society of America (OSA) web site: http://www.osa.org

3. International Society for Optical Engineering (SPIE) web site: http://www.spie.org

4. Center for Occupational Research and Development (CORD) web site: http://www.cord.org 